Edu Consilium: Jurnal BK Pendidikan Islam Vol 2, No. 1, Februari 2021, hlm. 74 - 86
ISSN 2503-3417 (online) ISSN 2548-4311 (cetak)

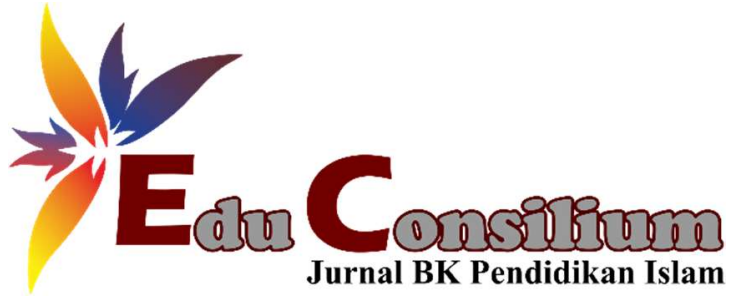

\title{
EFEKTIVITAS TEKNIK COGNITIVE RESTRUCTURING UNTUK MENURUNKAN TINGKAT KECEMASAN SISWA SAAT PRESENTASI DI DEPAN KELAS DI MTS AL-MUKHLISHIN GALIS
}

\author{
Luluk Atul Jannah
}

Program Studi Bimbingan dan Konseling Pendidikan Islam, Fakultas Tarbiyah, IAIN Madura *e-mail: Lutul.98@gmail.com

\section{Keywords: \\ Cognitive \\ Restructurin; \\ Anxiety ;}

Presentation.

\section{Abstract}

This research is based on the Cognitive Restructuring Technique to reduce students' anxiety levels when presenting in front of the class. This technique is very suitable to be used to reduce students' anxiety levels because in the Cognitive Restructuring technique it changes negative student thought patterns into more positive ones so as to reduce feelings of anxiety during presentations in front of the class.This research is an experimental study with a background at MTs Al-Mukhlisin Galis. The aim of this research is to test the Cognitive Restructuring Technique in reducing students' anxiety levels during presentations to the class at MTs Al-Mukhlisin Galis. This research uses pre-experimental research with pre-test and post-test, namely the initial measurement and the final measurement. The data collection methods used were questionnaires and interviews to determine changes in students' anxiety levels during presentations in front of the class after being given the Cognitive Restructuring technique. The research subjects were 6 people. The data analysis technique used is the non-parametric statistical analysis technique with the Wilcoxon signed level test.The results showed that; 1) Cognitive Restructuring techniques can reduce students' anxiety levels during presentations in front of the class. 2) there is a difference in students' anxiety level scores between before and after being given the Cognitive Restructuring technique. Based on the results of the Wilcoxon level test, it is known that $T$ count $=0, N=6$ students with a significant level of $5 \%$, then $T$ table is 1 which means $\mathrm{T}$ count is smaller $\mathrm{T}$ table ( $\mathrm{T}$ count $\leq \mathrm{T}$ table) which means Ho is rejected and Ha is accepted. It can be concluded that the Cognitive Restructuring technique is effective in reducing students' anxiety levels when presenting to class at MTs Al-Mukhlisin.

\begin{tabular}{cl}
\hline & \multicolumn{1}{c}{ Abstrak: } \\
\hline Kata Kunci: & Penelitian ini dilatar belakangi Teknik Cognitive Restructuring untuk menurnkan tingkat \\
Restrukturisasi & kecemasan siswa saat presentasi didepan kelas. Teknik ini sangat cocok digunakan untuk \\
Kognitif; & menurunkan tingkat kecemasan siswa karena dalam teknik Cognitive Restructuring \\
Kecemasan ; & $\begin{array}{l}\text { mengubah pola pikir siswa yang negatif menjadi pola pikir yang lebih positif sehingga } \\
\text { Presentasi . }\end{array}$ \\
dapat mengurangi perasaan cemas saat presentasi di depan kelas. Penelitian ini \\
\hline
\end{tabular}


merupakan penelitian eksperimen dengan mengambil latar di MTs Al-Mukhlisin Galis. Tujuan yang ingin dicapai dalam penelitian ini adalah untuk menguji Teknik Cognitive Restructuringdalam menurunkan tingkat kecemasan siswa saat presentasi di depan kelas di MTs Al-Mukhlisin Galis. penelitian ini menggunakan jenis penelitian preeksperimental dengan pre-test dan post-test yaitu pengukuran awal dan pengukuran akhir. Metode pengumpulan data yang digunakan adalah angket dan wawancara untuk mengetahui perubahan tingkat kecemasan siswa saat presentasi di depan kelas setelah diberikan teknik Cognitive Restructuring. Subjek penelitian sebanyak 6 orang. Teknik analisis data yang digunakan adalah teknik analisis statistik non parametrik dengan uji jenjang bertanda wilcoxon. Hasil Penelitian menunjukkan bahwa; 1) teknik Cognitive Restructuring dapat menurunk an tingkat kecemasan siswa saat presentasi di depan kelas. 2) terdapat perbedaan skor tingkat kecemasan siswa antara sebelum dan sesudah diberikan teknik Cognitive Restructuring. Berdasarkan hasil uji jenjang wilcoxon diketahui $\mathrm{T}$ hitung $=0, \mathrm{~N}=6$ siswa dengan taraf signifikan $5 \%$, maka $\mathrm{T}$ tabel sebesar 1 yang berarti $\mathrm{T}$ hitung lebih kecil $\mathrm{T}$ tabel ( $\mathrm{T}$ hitung $\leq \mathrm{T}$ tabel) yang berarti Ho ditolak dan $\mathrm{Ha}$ diterima. Hal ini disimpulkan bahwa teknik Cognitive Restructuring efektif dalam menurunkan tingkat kecemasan siswa saat presentasi di depan kelas di MTs Al-Mukhlisin.

\section{PENDAHULUAN}

Sekolah merupakan tempat yang paling baik untuk siswa. Di sekolah siswa melakukan proses belajar. Siswa adalah pribadi yang akan berkembang menjadi dewasa. Dengan bertambahnya usia, siswa belajar mulai dari titik nol dari sebelum ia mengetahui menjadi tahu. Dalam proses pembelajaran inilah dibutuhkan seseorang yang benar-benar bisa memahaminyamaka dari itu dibutuhkan seorang guru yang dapat mendampingi siswa. Di dalam sekolah semua guru menjadi penanggung jawab bagi semua siswanya terutama dalam proses belajar mengajar.Selain menyampaikan ilmu pengetahuan guru juga haerus membimbing siswanya untuk menjadi siswa yang mandiri dan sukses meraih keberhasilan. Salah satu cara yang sudah sering dilakukan agar siswa berani dan mandiri di dalam kelas adalah Presentasi.

Presentasi yaitu penyampaian materi yang dilakukan oleh siswa di depan kelas. Presentasi bermakna sebagai tindakan menginformasikan kembali ide, gagasan yang dilaksanakan secara terstruktur (Herri Susanto, 2004: 150). Presentasi sudah lumrah dilakukan di semua jenjang pendidikan, di Sekolah Dasar, di Sekolah Menengah Pertama, di sekolah Menengah Atas (SMA), bahkan diperguruan tinggi sudah sangat sering dilakukam dengan tujuan menyampaikan informasi materi kepada siswa lain. Presentasi digunakan untuk menggali berbagai informasi, menyerap, dan mengolahnya sampai menghadirkan kembali informasi tersebut kepada teman sekelas. 
Banyak siswa yang berpendapat bahwa presentasi adalah hal yang sangat menegangkan dan menakutkan, sehingga kurang disukai oleh beberapa siswa. Ketakutan ketakutan yang muncul dari siswa disebabkan oleh siswa itu sendiri dan juga disebabkan oleh strategi yang digunakan dan kurangnya kesiapan materi pada saat melakukan presentasi. Untuk mengatasi masalah yang muncul pada diri siswa tersebut maka guru harus memiliki metode pembelajaran yang lebih kreatif dan menyenangkan agar siswa dapat presentasi di depan kelas dengan tenang.

Salah satu cara atau metode yang digunakan guru agar dapat mengetahui siswa tersebut paham atau tidak terhadap materi yang disampaikan ketika presentasi di depan kelas yaitu dengan melihat cara penyampaian materi yang disampaikan oleh siswa ketika berada di depan teman-teman sekelasnya. sebagian siswa yang paham mengenai materi yang disampaikan menganggap hal tersebut (Presentasi) bukanlah suatu masalah, akan tetapi sebagian siswa yang kurang mengerti mengenai materi yang akan di sampaikan di depan kelas akan menganggap hal tersebut sebagai suatu tekanan sehingga mereka akan cemas ketika guru menyuruh presentasi di depan kelas.

Dalam kondisi seperti ini, seringkala siswa akan berfikir negatif, berfikir yang salah terhadap dirinya sendiri yang dapat mendownkan siswa itu sendiri. Seperti "saya Malu", "saya takut tidak bisa melakukannya","saya takut salah","saya takut tidak bisa menjawab pertanyaan", atau mungkin ada siswa lain yang tidak membenarkan tindakannya . Hal itu mengakibatkan siswa tidak dapat berkonsentrasi pada saat presentasi di depan kelas. Sehingga tidak dapat melakukan presentasi secara maksimal. Padahal dalam kegiatan pembelajaran siswa yang harus lebih aktif dikelas. Serta keberanian mereka akan menjadi poin tersendiri bagi siswa. Apabila siswa berhasil maka akan ada peningkatan terhadap prestasi belajar siswa. Akan tetapi, apabila siswa tidak berhasil akan berdampak pada hasil belajar siswa.

Seperti yang dikemukaan oleh Kirkland yang membuat suatu kesimpulan bahwa kecemasan yang sedang ataupun kecemasan yang tinggi berpengaruh terhadap hasil belajar siswa. Baik dapat mendorong siswa itu lebih belajar atau malah lebih mengganggu hasil belajar siswa (Anggia Maretta, Dkk, 2018:3) Kecemasan dapat berpengaruh terhadap proses dan hasil belajar siswa. mereka merasa prihatin terhadap dirinya dan khawatir ketika mereka menghadapi tantangan-tantangan di sekolah.Kecemasan atau Anxietas dapat mempengaruhi tingkah laku yang ditimbulkan dari ancaman -ancaman berupa rasa khawatir, takut yang tidak jelas sebabnya yang ditimbulkan dari perasaan-perasaan yang kurang benar yang menurutnya 
ada sesuatu yang tidak bisa diterimanya seperti yang ada di pikiran yang sedang menghantuinya sehingga berpengaruh terhadap tingkah laku siswa (Singgih D. Gunarsa, 2008:27).

Kecemasan adalah suatu hal yang akan memperingatkan akan adanya ancaman bahaya yang biasa ditandai dengan perasaan tegang yang akan membuat kita salah tingkah dalam melakukan sesuatu (Gerald Corey ,2013:17. Timbulnya kecemasan itu dari diri sendiri yang dapat menjadikan kita seolah-olah tidak berdaya, yang dapat menurunkan konsentrasi, daya ingat menurun. Jika kecemasan mulai mengacaukan emosi, maka akan mengakibatkan prestasi tidak optimal dan kinerja siswa pada saat Presentasi tidak maksimal.

Kecemasan yang menyebabkan seseorang menjadi putus asa adalah kecemasan yang negatif, Orang yang berfikiran negatif akan mempunyai pandangan yang negatif pula dan menganggap pikiran tersebut sebagai suatu kenyataan sehingga dapat membuat kecemasan pada diri sendiri. Kecemasan terjadi karena pikiran berfokus pada prasangka-prasangka yang belum terjadi. Masalah yang dialami oleh siswa merupakan akibat dari siswa yang selalu mengedepankan pikiran takut salah yang dapat mempengaruhi sikap dan juga siswa yang selalu mengedepankan keyakinan-keyakinan yang salah dalam diri siswa itu sendiri.

Berpikiran negatif adalah suatu yang belum pasti benar-benar akan terjadi, oleh karena itu Allah SWT. melarang hamba-Nya berfikiran negatif dan Memerintahkan hambaNya untuk selalu berfikir positif. Jadi cobalah untuk berserah diri kepada Allah SWT. seperti yang dijelaskan dalam Al-Quran Surah Al-Baqarah (Nico Manggala, 2015: 38)

\footnotetext{
$\Delta \square \rightarrow \Omega \wedge \square$ Kं ঠ口四 \& \&

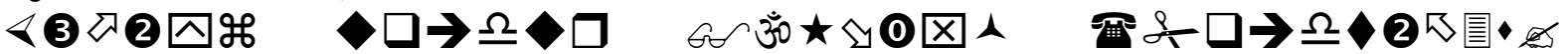

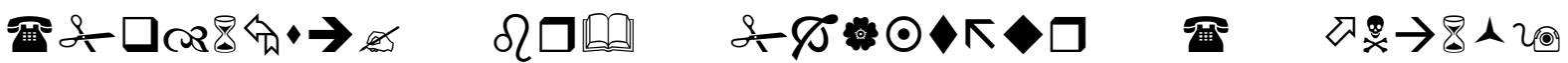

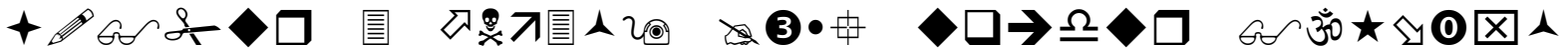

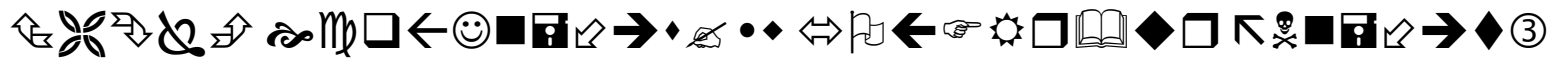
Artinya: "Diwajibkan kalian semua berperang meskipun itu terlihat tidak menyenangkan bagi kalian, tapi bisa jadi hal yang tidak menyenangkan bagi kalian adalah hal yang terbaik untuk kalian. Dan boleh saja kamu melakukan sesuatu yang menurutmu baik bagimu, bisa jadi itu tidak baik bagimu. Allah yang mengetahui semua yang baik dan yang tidak baik bagimu.". (QS. Al- Baqarah: 216), (Mushaf Aqillah, 2010: 34)

Dalam surah ini dijelaskan. Maka hendaklah kita berfikir positif. Dengan berpikir positif, maka akan mengubah hidup menjadi lebih baik, lebih tenang, lebih optimis, dan menghindari sikap pesimis, takut gagal, dan pikiran-pikiran negatif lainnya.
} 
Melihat dampak negatif dari kecemasan pada saat prentasi, maka harus mencari cara untuk mengurangi dan mencegah kecemasan siswa. Maka perlu mendapatkan bantuan tenaga pendidik yaitu guru BK dalam menangani kecemasan yag dialaminya dan juga guru mata pelajaran dalam penguasaan materi agar siswa dapat melakukan presentasi secara optimal.

Untuk mengatasi kecemasan pada saat Presentasi, diperlukan alternatif bantuan dalam bimbingan dan konseling yaitu dengan menggunakan Teknik pengubahan pola pikir yaitu teknik Cognitive Restructuring. Teknik ini dapat digunakan untuk mengubah pikiran yangsalah menjadi pikiran yang lebih masuk akal atau lebih positif, dan membantu siswa mengubah keyakinan akan kegagalan. Menurut Cormier dan Cormier, teknik ini dapat mengidentifikadsi pikiran yang salah yang dapat merusak diri dan menggantinya dengan pikiran yang positif yang dapat menguatkan dirinya. Teknik Cognitive Restructuring ini berpusat pada pola pikiran yang salah yang kemudian diidentifikasi dan mengubahnya ke pikiran yang menguatkan yaitu pikiran yang positif. Prinsip CR didasarkan pada Anggapannya bahwa segala bentuk perilaku itu dipengaruhi oleh pikiran, persepsi dari individu itu sendiri yang dapat memunculkan perilaku yang sengaja dan berdampak negatif bagi dirinya sendiri.Teknik Cognitive Restructuring dapat mengetahui pikiran apa saja yang salah dan mengenalinya serta menggantinya dengan pikiran yang lebih positif sehingga dapat menghilangkan pikiran yang salah tersebut (Nursalim, 2013: 32)

Cognitive Restructuring ini disebut juga dengan pengubahan pola fikir yang menyangkal proses berpikir yang salah atau pikiran yang tidak rasional dan menggantinya dengan pikiran yang menguatkan yaitu pikiran yang positif. Teknik Cognitive Restructuring menerapkan prinsip belajar pada pikiran. Teknik Cognitive Restructuring di dasarkan pada dua anggapan bahwa pikiran irrasional dapat menghasilkan perilaku yang disengaja oleh siswa yang akan memunculkan perilaku yang tidak diinginkan atau perilaku yang negatif terhadap siswa itu sendiri. Yang kedua,pikiran yang ada pada diri siswa dapat diubah oleh siswa itu sendiri melaui perubahan pikira diri siswa itu sendiri (Harwanti Noviandari, 2006: 78). Jadi semua tindakan yang akan dilakukan oleh siswa itu berada di tangan siswa itu sendiri.

Berdasarkan Latar Belakang masalah diatas, peneliti perlu membuktikan kebenarannya antara teori dan realita. Maka peneliti tertarik untuk melakukan penelitian tersebut yaitu tentang “Efektivitas Teknik Cognitive Restructuring Untuk Menurunkan Tingkat Kecemasan Siswa Saat Presentasi di Depan Kelas di MTs Al- Mukhlisin Galis” yang bertujuan untuk mengetahui penerapan Teknik Cognitive Restructuring dapat menurunkan 
tingkat kecemasaan siswa saat presentasi di depan kelas serta untuk mengetahui perbedaan skor kecemasan siswa saat presentasi di depan kelas antara sebelum dan sesudah diberikan Teknik Cognitive Restructuring pada siswa MTs Al-Mukhlisin Galis.

Hipotesis dalam penelitian ini ;

Ha: (1) Teknik Cognitive Restructuring dapat Membantu siswa menurunkan tingkat kecemasan saat Presentasi di depan kelas, (2) Ada perbedaan skor kecemasan siswa saat presentasi di depan kelas antara sebelum diberikan teknik Cognitive Restructuring dan sesudah diberikan Teknik Cognitive Restructuring. 


\section{METODE}

Penelitian ini merupakan penelitian Eksperimen, karena dalam penelitian ini melakukan (treatmen) atau perlakuan. Menurut Ary, Jacobs dan Razavieh dalam Purwanto, Eksperimen merupakan kegiatan yang direncanakan dan dilaksanakan oleh peneliti untuk mengumpulkan bukti-bukti yanag ada hubungannya dengan Hipotesis (Purwanto, 2008). Metode penelitian Eksperimen adalah metode penelitian yang digunakan untuk mencari pengaruh perlakuan tertentu terhadap yang lain dalam kondisi yang terkendali (Sugiyono, 2010 .

Penelitian ini menggunakan design Pre-Experimental, karena tidak menggunakan variabel kontrol dan sampel tidak dipilih secara acak tetapi dipilih secara purposive sampling yaitu cara memilih sampel dengan tujuan. Bentuk rancangan penelitian ini menggunakan One-Group Pretest-Posttestyaitu dengan memakai pengukuran awal dan akhir, sehingga dapat membandingkan keadaan sebelum diberi perlakuan dan setelah diberi perlakuan.

Teknik ini diberikan untuk mengetahui seberapa besar pengaruhnya terhadap kecemasan siswa saat presentasi di depan kelas.

Penelitian ini akan dilakukan seperti gambar :

$\mathrm{O} 1$

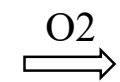

Keterangan: $\mathrm{O} 1=$ nilai Pretest (sebelum diberi perlakuan)

$\mathrm{O} 2=$ Nilai post test (setelah diberi perlakuan)

$\mathrm{X}=$ Treatmen

\section{Gambar 1: One-Group Pretest-Posttest}

Prosedur penelitian :

1. Memberikan angket kecemasan (O1) untuk mengetahui tingkat kecemasan siswa yang mempunyai skor kecemasan tinggi saat presentasi di depan kelas kepada siswa kelas VIII di MTs Al-Mukhlisin Galis.

2. Setelah mengetahui siswa yang mengalami skor kecemasan tertinggi saat presentasi di depan kelas, maka di panggil siswa yang mengalami kecemasan tertinggi saat presentasi di depan kelas sebanyak 6 orang yang di ambil dari siswa yang memiliki skor kecemasan tertinggi dan diberikan perlakuan (tretment) berupa teknik pengubahan pola pikir (Cognitive Restructuring).

3. Setelah diberikan Teknik Cognitive Restructuring maka diberikan angket kecemasan berikutnya $(\mathrm{O} 2)$ yang diberikan kepada subjek penelitian sebanyak 6 porang untuk 
mengetahui apakah ada perubahan atau tidak setelah diberikan perlakuan teknik Cognitive Restructuring.

4. Hasil dari angket $\mathrm{O} 1$ dan $\mathrm{O} 2$ dibandingkan untuk mengetahui tingkat perbedaan yang terjadi setelah diberikan angket dengan menggunakan uji jenjang wilcoxon.

\section{HASIL}

Dari hasil pengukuran awal dan pengukuran akhir yang telah dilakukan maka langkah yang dilakukan yaitu analisis data dengan membandingkan hasil pengukuran awal dan pengukuran akhir. Karena datanya adalah data non parametrik maka analisis datanya dengan menggunakan uji jenjang Wilcoxon yang memang digunakan untuk menganalisis data yang sifatnya non parametrik. Jadi dalam hal ini peneliti menggunakan analisis data wilcoxon untuk mengetahui benar atau tidaknya hipotesis yang peneliti gunakan yaitu dengan bantuan SPSS Versi 25,0.

Hipotesis yang ada yang digunakan oleh peneliti adalah Teknik Cognitive Restructuring dapat menurunkan tingkat kecemasan siswa saat presentasi di depan kelas di MTs Al-Mukhlisin Galis yang berarti bahwa terdapat skor yang beda pada saat diberikan pengukuran awal dan pengukuran akhir setelah diberikan tretment.

Untuk menganalisis data, peneliti menggunakan analisis uji jenjang wilcoxon.Kriteria penerimaan hipotesis uji wilcoxon diterima atau di tolak apabila $r$ hitung $\leq \mathrm{r}$ tabel berarti Hipotesis 0 ditolak dan Hipotesis Alternatif diterima, namun bila $r$ hitung $\geq r$ tabel maka Hipotesis 0 di terima dan Hipotesis alternatif di tolak.

Tabel 1. Hasil Pre-test dan Post-test

\begin{tabular}{|c|c|c|c|c|c|c|c|}
\hline \multirow{2}{*}{ No } & \multirow{2}{*}{ Nama } & \multirow{2}{*}{ Pre-Test } & \multirow{2}{*}{$\begin{array}{c}\text { Post- } \\
\text { Test }\end{array}$} & \multirow{2}{*}{ Beda } & \multicolumn{3}{|c|}{ Tanda Jenjang } \\
\cline { 5 - 9 } & NAZH & 84 & 74 & 10 & 2 & - & 2 \\
\hline 1 & NSB & 92 & 78 & 14 & 3 & - & 3 \\
\hline 3 & AHAS & 86 & 68 & 18 & 5 & - & 5 \\
\hline 4 & SLSTN & 89 & 52 & 37 & 6 & - & 6 \\
\hline 5 & FZH & 80 & 74 & 6 & 1 & - & 1 \\
\hline 6 & ERVNA & 90 & 74 & 16 & 4 & - & 4 \\
\hline
\end{tabular}


Dari hasil di atas jelas bahwa hasil uji wilcoxon yang berjumlah negatif selisihnya sebesar 21, dan untuk hasil yang berjumlah positif sebesar 0 . Untuk mengetahui t hitung maka dapat dilihat dari hasil uji jenjang wilcoxon yang paling kecil tanpa melihat tandanya yaitu jumlah urut yang paling kecil $=0$. Jadi thitungnya $=0$. Untuk nilai kritis $\mathrm{T}$ uji wilcoxon dengan taraf signifikan $5 \%$ sudah ditentukan bahwa untuk $\mathrm{N}$ sebanyak 6 orang maka $\mathrm{t}$ tabelnya sebesar $=1$. Sehingga dapat dilihat dari hasil uji jenjang wilcoxon $\mathrm{t}$ hitung sebesar $=$ 0 , dan $\mathrm{t}$ tabel sebesar $=1$. Apabila $\mathrm{t}$ hitung lebih kecil dari pada $\mathrm{t}$ tabel maka Ho ditolak, apabila Ho ditolak berati Ha diterima..

Dari hasil uji yang dilakukan di atas sudah diketahuit hitung lebih kecil dari pada $t$ tabel $(0 \leq 1)$, maka dugaan penelitian (hipotesis) dapat diterima. Dengan ini teknik CR bisa mengurangi tingkat kecemasan siswa saat prsentasi di depan kelas pada siswa kelas 8 di MTs Al-Mukhlishin Galis setelah mendapat perlakuan dengan teknik Cognitive Restructuring. Jadi hipotesis yang berbunyi “ Teknik Cognitive Restructuring dapat menurunkan tingkat kecemasan siswa saat presentasi di depan kelas di MTs Al-Mukhlisin"dapat diterima.

Untuk melihat kejelasan data yang mengalami penurunan dari pengukuran awal dan pengukuran akhir dapat dilihat dari diagram dibawah ini:

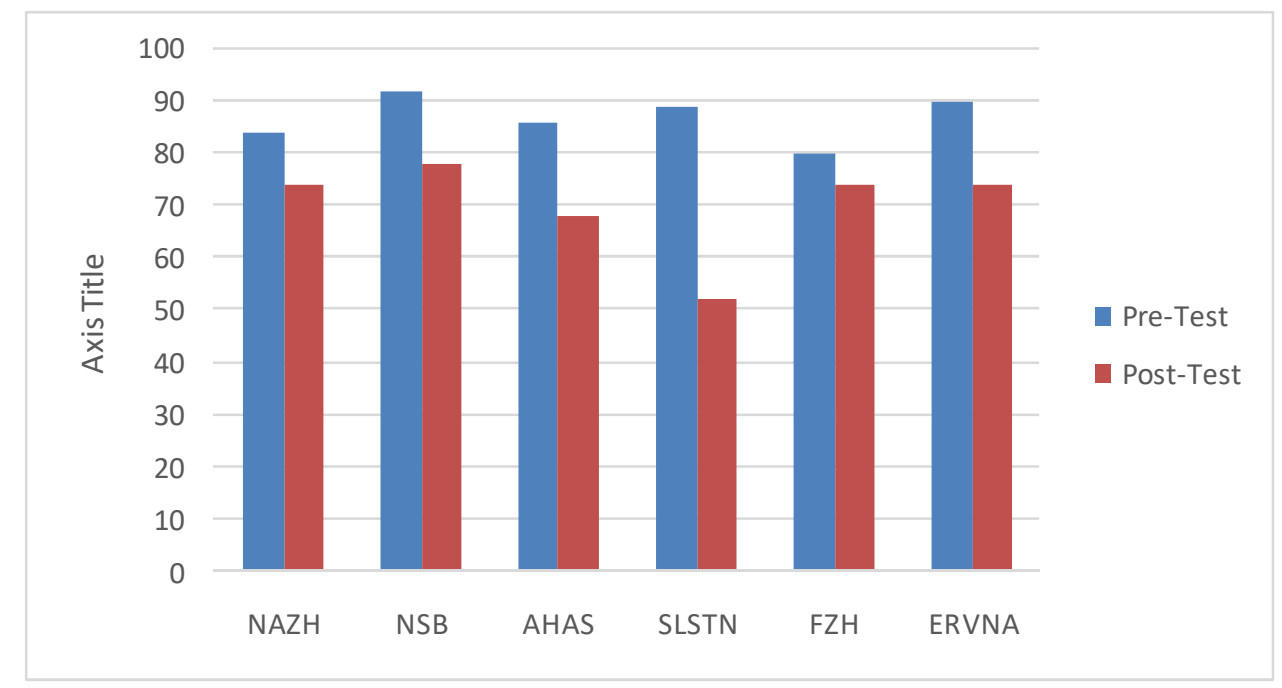

\section{Diagram 1. Hasil Pengukuran Awal dan Pengukuran Akhir Skala kecemasan Saat Presentasi di depan kelas}

Dapat dilihat dari hasil diagram di atas bahwa yang bertanda biru adalah pengukuran awal dan yang berwarna orange adalah pengukuran akhir. Jadi dapat dilihat adanya skor yang berbeda antara pre-test (pengukuran awal) dan posttest (pengukuran akhir) tingkat kecemasan siswa saat presentasi di depan kelas. Untuk grafik pre-test lebih tinggi dibandingkan grafik post-test (pengkuran akhir). Hal ini menjelaskan terdapat perbedaan hasil pre-test 
(pengukuran awal) dan post-test (pengukuran akhir) bahwa ada penurunan skor kecemasan saat presentasi di depan kelas antara sebelum diberikan teknik Cognitive Restructuring dan sesudah diberikan teknik cognitive restructuring.

\section{PEMBAHASAN}

Teknik Cognitive Resructuring adalah teknik pengubahan pola pikiran yang salah yang sifatnya negatif dirubah ke dalam pikiran yang dapat menguatkan yang sifatnya positif. Teknik cognitive restructuring di lakukan kepada siswa yang mengalami rasa cemas yang berlebihan ketika sedang presentasi di depan kelas. Kegiatan ini sudah sering di laksanakan diberbagai jenjang pendidikan, namun masih banyak yang mengalami kecemasan.

Berdasarkan instrumen penelitian Pre-test kecemasan saat presentasi di depan kelas, enam siswa yang memiliki skor kecemasan tinggi dijadikan subjek penelitian. Keenam siswa tersebut diberikan treatmen berupa teknik Cognitive Restructuring, dimana setiap siswa diberikan kesempatan untuk mengutarakan permasalahan yang berkaitan dengan rasa cemas yang mereka alami. Perasaan cemas yang muncul ketika mereka dihadapkan pada suatu keadaan yang menekan keadaan emosional. Khususnya pada saat presentasi di depan kelas tanpa alasan dapat menimbulkan pikiran-pikiran negatif yang timbul dalam diri siswa sehingga mengalami kecemasan.

Dari hasil ini diperoleh $\mathrm{T}$ hitung $=0$ dan $\mathrm{T}$ tabel $=1$ sehingga Hipotesis diterima. Hal ini berarti Teknik Cognitive Restructuring dapat menurunkan tingkat rasa cemas pada diri siswa saat presentasi di depan kelas karena $\mathrm{T}$ hitung $\leq \mathrm{T}$ tabel. Menurunnya tingkat kecemasan siswa juga didukung oleh pernyataan siswa setelah diberikan teknik Cognitive Restructuring bahwa sekarang mereka sudah mulai berani presentasi kedepan kelas dan menghilangkan fikiran yang dapat membuat mereka cemas ketika presentasi di depan kelas yang artinya siswa sudah mulai bisa mengontrol pikirannya sendiri.

Dalam hal ini semua siswa tidak mengalami pengurangan atau penurunan skor yang sama artinya skor penurunan siswa berbeda ada yang hanya mengalami penurunan sebesar 6 namun ada juga yang mengalami penurunan nilai sebesar 30. Karena setiap siswa tidak sama dan memiliki kemampuan yang berbeda. Ada siswa yang belum bisa sepenuhnya menerima penjelasan, intruksi yang sudah diberikan namun ada juga siswa yang langsung peka yang memiliki kesadaran diri dan langsung melaksanakan prosedur yang telah diberikan.

Efektivitas teknik Cognitive Restructuring untuk menurunkan rasa cemas siswa saat presentasi di depan kelas dapat di lihat dari hasil uji hipotesis di atas. Apabila Ha diterima 
berarti teknik cognitive restructuring efektiv dalam menurunkan tingkat kecemasan siswa saat presentasi, namun apabila dari hasil uji hipotesis Ha di tolak berarti teknik cognitive restructuring tidak dapat menurunkan tingkat kecemasan siswa saat presentasi di depan kelas.

Dari hasil uji hipotesis di atas diketahui t hitung lebih kecil dari pada $t$ tabel ( $t$ hitung $\leq \mathrm{t}$ tabel) sehingga apabila $\mathrm{t}$ hitung lebih kecil dari pada $\mathrm{t}$ tabel ( $\mathrm{t}$ hitung $\leq \mathrm{t}$ tabel) berarti Ho ditolak dan Ha di terima begitupun sebaliknya apabila $\mathrm{t}$ hitung lebih besar dari pada $\mathrm{t}$ tabel ( $\mathrm{t}$ tabel $\geq t$ hiung ) maka Ho diterima dan Ha ditolak.

Dari hasil uji jenjang wilcoxon sudah membuktikan bahwa siswa mengalami penurunan tingkat kecemasan saat presentasi di depan kelas setelah diberikannya konseling individu dengan treatment Cognitive Restructuring. Hal ini sudah terbukti bahwa teknik Cognitive restructuring efektif dalam menurunkan tingkat kecemasan siswa saat presentasi di depan kelas.

\section{SIMPULAN}

Teknik Cognitive Restructuring merupakan teknik yang dapat mengubah pola pikir yang negatif menjadi pola pikir yang positif. dalam penelitian ini peneliti telah menguji bahwa teknik Cognitive Restructuring memiliki efektivitas dalam menurunkan tingkat kecemasan siswa saat presentasi di depan kelas. melalui penelitian ini peneliti mencapai tujuan yaitu membantu siswa dalam menurunkan tingkat kecemasannya ketika sedang presentasi di depan kelas. hal ini telah dibuktikan dari perbedaan skor antara sebelum dan sesudah diberikan treatmen bahwa perbedaannya terlihat jelas. sehingga teknik cognitive restructuring efektif dalam mengubah pola pikir siswa yang negatif sehingga mampu menurunkan tingkat kecemasannya saat presentasi di depan kelas.

\section{DAFTAR RUJUKAN}

Aqillah, Mushaf, Al-Quran Terjemah dan Tafsir untuk Wanita Tafsir Ibnu Katsir, Tafsir AthThabari, Asbabun Nuzul, Doa dan Zikir Sehari-Hari. Bandung: JABAL. 2010.

Budi Ra'I. Memilih Uji Statistik Dalam Penulisan Skripsi. Surabaya: Unesa University Press. 2000.

Corey, Gerald. Teori dan Praktek Konseling \& Psikoterapi. Bandung: PT Refika Aditama. 2013.

Cristy, Chintia Diana, Dkk. Penggunaan Strategi Cognitive Restructuring (CR) Untuk Meningkatkan Efikasi Diri Siswa Kelas X-TSM-1 SMK Negeri 1 Mojokerto, Junal BK UNESA, Volume 04(01) 2013.

Damayanti, Rika, Dkk. Pengaruh Konseling Kognitif Perilaku Dengan Teknik Restruturisasi Kognitif Terhadap Harga Diri Peserta Didik Kelas VIII Di MTs N 2 Bandar Lampung, Jurnal Bimbingan dan Konseling, (Volume 3 (2), 2015. 
Fajaruddin, Titin Indah Pratiwi, Penerapan Strategi Cognitive Restructuring Untuk Menurunkan Persepsi Negatif Terhadap Pelaksanaan Program Bimbingan dan Konseling Pada Siswa Kelas X SMA Negeri 1 Karangrejo Tulungagung, jurnal BK, Volume 06 (01), 2016.

Gunarsa, Singgih D. Psikologi Perawatan. Jakarta: PT BPK Gunung Mulia. 2008.

Manggala, Nico. 9 Terapi Untuk Kecemasan Berlebihan (Ansietas). Surabaya: CV Garuda Mas Sejahtera. 2015.

Noviandari, Harwanti, Jawahirul Kawakib. Teknik Cognitive Restructuring Untuk Meningkatkan Self Efficacy Belajar Siswa. Jurnal Psikologi. Volume 3(2). 2006

Nursalim, Mochammad. Strategi \& Intervensi Konseling. Jakarta: PT Indeks. 2013.

Purwanto. Metodologi Penelitian Kuantitatif untuk Psikologi dan Pendidikan. Yogyakarta: PUSTAKA PELAJAR. 2008.

Sugiyono. Metode Penelitian Kuantitatif Kualitatif Dan R\&D. Yogyakarta: Bandung: ALFABETA. 2010

Sulhan, Najib. Pembangunan Karakter Pada Anak Manajemen Pembelajaran Guru Menuju Sekolah Efektif. Surabaya: SIC Bekerja Sama Dengan Yayasan Al-Azhar Kelapa Gading Surabaya. 2006.

Susanto, Herri. Communication skills "Sukses Komunikasi, Presentasi, dan Berkarier". Yogyakarta: CV Budi Utama. 2004. 